\title{
Single nucleotide polymorphisms are suitable for assessing the success of restocking efforts of the European lobster (Homarus gammarus, L.)
}

\author{
Pierre De Wit ${ }^{1}$ (D) $\cdot$ Linda Svanberg ${ }^{2,3} \cdot$ Isabel Casties $^{2,3} \cdot$ Susanne P. Eriksson ${ }^{2,3} \cdot$ Kristina SundelI $^{2,3} \cdot$ Carl André $^{1}$
}

Received: 2 March 2021 / Accepted: 17 August 2021 / Published online: 27 August 2021

(c) The Author(s) 2021

\begin{abstract}
The European lobster (Homarus gammarus) forms the base of an important fishery along the coasts of Europe. However, stocks have been in decline for many years, prompting new regulations in the fishery and also restocking efforts. An important feature of any restocking effort is the assessment of success in the number of released juveniles that stay and become adult over time. Here, we tested the power of a single nucleotide polymorphism (SNP) DNA marker panel developed for population assignment to correctly infer parentage on the maternal side of lobster larvae, in the absence of known fathers, using lobsters included in a current restocking effort on the Swedish west coast. We also examined the power to reconstruct the unknown paternal genotypes, and examined the number of fathers for each larval clutch. We found that the 96-SNP panel, despite only containing 78 informative markers, allowed us to assign all larvae to the correct mother. Furthermore, with ten genotyped larvae or more, confident paternal genotypes could be reconstructed. We also found that 15 out of 17 clutches were full siblings, whereas two clutches had two fathers. To our knowledge, this is the first time a SNP panel of this size has been used to assess parentage in a crustacean restocking effort. Our conclusion is that the panel works well, and that it could be an important tool for the assessment of restocking success of H. gammarus in the future.
\end{abstract}

Keywords Homarus gammarus $\cdot$ European lobster $\cdot$ Restocking $\cdot$ Parental assignment $\cdot$ SNP genotyping

\section{Introduction}

The world's oceans are continuously experiencing stronger and stronger fishing pressure, and presently there are few fisheries that are exploited less than to the maximum sustainable yield. In addition, about $30 \%$ of the world's marine fish stocks are currently fished at biologically unsustainable levels (FAO 2020), a fraction which is currently increasing. As a consequence, a number of actions have been undertaken in order to minimize unsustainable practices, including implementation of no-take zones, fishing quotas, size limits, along

Pierre De Wit

pierre.de_wit@marine.gu.se

1 Department of Marine Sciences, University of Gothenburg, Gothenburg, Sweden

2 Department of Biological and Environmental Sciences, University of Gothenburg, Gothenburg, Sweden

3 The Swedish Mariculture Research Center (SWEMARC), Gothenburg, Sweden with stricter enforcement of regulations (FAO 2020). Many fisheries have also introduced restocking efforts, where fish or shellfish are raised in aquaculture environments from eggs to juvenile life stages, and then released into the wild (reviewed in e.g. Halverson 2008; Taylor et al. 2017). In order to distinguish hatchery-reared individuals from wild ones in later life stages, a variety of different methods have been used, including different types of staining (Camp et al. 2013) and electronic tags (Nzau Matondo et al. 2019). However, the large-scale effects of restocking efforts have to date been difficult to assess, and in many small-scale efforts where evaluations have been possible the costs seem to outweigh the benefits (Kitada 2018).

The European Lobster (Homarus gammarus) is the base for an important local fishery all along the coast of Europe. Despite this, there are currently no EU-common regulations for the fishery (Bryhn et al. 2020). Along the Swedish west coast, the lobster fishery is to a large extent recreational, and although there is no record of the number of landings from the recreational fishery, it was estimated to account for almost $90 \%$ of total Swedish used traps, and 
75\% of total landings in 2007 (Bryhn et al. 2020). Lobster stocks have not been officially monitored in Swedish waters to date, making it difficult to assess whether they are overfished, but the number of landings as well as the catch per unit effort have both steadily decreased since the 1960s, indicating that the stock is declining (Sundelöf et al. 2013; Bryhn et al. 2020). Similar trends have also been seen in other North Sea lobster stocks, in Norway and in the UK (Bryhn et al. 2020). As a consequence, regulations for the recreational fishery have been tightened in recent years in Sweden, with a lowered number of traps per person allowed, and higher minimum landing size limits.

In addition to the stricter regulations, a restocking effort has recently been introduced on the Swedish west coast, where ovigerous females are supplied by local lobster fishers, and the larvae are hatched in aquaculture facilities. After that, the lobster larvae are reared until ready to settle on the benthos, after which they are released at selected sites in the same area where their mothers were caught. Restocking has been taking place since 2018, with the expectation that the first outplanted lobsters will have grown above the minimum landing size in the fall of 2022. Estimating the success of the restocking effort will be of crucial importance to the fishery at that point.

In order to accurately determine if a caught lobster is laboratory-hatched or not, genetic analyses are optimal (Ellis et al. 2015b). With known parental genotypes, it is possible to assess whether an individual juvenile is the progeny of any of the known genotypes or not, given a large enough panel of genetic markers. These so-called assignment tests have been used for parentage analysis for a long time, based on microsatellite markers (Ellis et al. 2015a). More recently, however, single nucleotide polymorphisms (SNPs) have replaced microsatellites as the most commonly used markers due to the abundance of such markers in most genome sequences, and the ease and reproducibility of genotyping (Flanagan and Jones 2019). Recently, a novel SNP panel of 96 markers was developed to test for population differentiation and population assignment among European stocks of H. gammarus (Jenkins et al. 2019a). This panel was shown to work well for the intended purpose (Jenkins et al. 2019b). However, it has to date not been tested for its power of parentage assessment.

Here, we applied the SNP panel developed by Jenkins et al. (2019a) to a dataset consisting of mothers, progeny and unrelated control individuals, in order to test the power to: (1) Assign juveniles to the correct mother; (2) Not incorrectly assign unrelated individuals to a mother. As pregnant females collected for the restocking effort in the wild were used, there was no information on potential father(s), so therefore an additional goal was to assess the power of the panel to: (3) Confidently reconstruct paternal genotypes.
In addition, the panel was used to (4) Investigate whether clutches were originating from one or several fathers.

\section{Materials and methods}

Lobster juveniles were reared at the Kristineberg Marine Research Station from wild-caught gravid females $(n=17)$, until ca. 2 months old, during 2018-2020 (Table 1). The females were caught in the Sotefjord (Sotefjorden, SE582700-110451) and transported to Kristineberg by local lobster fishermen. They were then kept over winter, in $40 \mathrm{~L}$ perforated boxes in a seawater flow-through system. The water was pumped up from $32 \mathrm{~m}$ depth in the Gullmar fjord and varied in salinity and temperature with the season, between $30.5-34.3$ PSU and $5.4-19.4{ }^{\circ} \mathrm{C}$ respectively. The females were fed fresh frozen shrimp (Pandalus borealis), and the embryo development in the egg clutches was checked routinely based on the eye index method developed by Perkins (1972). The females were brought over in pairs to a separate hatching system and placed in separate $40 \mathrm{~L}$ boxes with the water outflow leading to a larval collection tank. The temperature was incrementally raised to $18.5 \pm 0.5^{\circ} \mathrm{C}$ $\left(1{ }^{\circ} \mathrm{C}\right.$ per day) to speed up the embryonal development. Upon hatching, the larvae were counted and transferred to the larvae rearing set up, at which point larvae and tissue samples were collected.

From each family unit, a pleiopod from the mother was removed and placed in 95\% ethanol, and newly hatched larvae ( $\mathrm{n}=10-30$ per family) were placed whole in $95 \%$

Table 1 Number of larvae and assignment statistics for genotyped mothers

\begin{tabular}{llrll}
\hline Year & Mother & $\mathrm{N}_{\text {larvae }}$ & $\mathrm{P}_{\text {assignment }}$ & $\mathrm{N}_{\text {fathers }}$ \\
\hline 2018 & M-S1 & 24 & 0.9841 & 1 \\
2018 & M-S2 & 10 & 0.999 & 1 \\
2018 & M-S5 & 10 & 0.9938 & 1 \\
2018 & M-S6 & 10 & 0.9932 & 1 \\
2018 & M-S8 & 9 & 0.9932 & 1 \\
2018 & M-S9 & 10 & 0.9346 & 1 \\
2019 & M-S13 & 9 & 0.9807 & 2 \\
2019 & M-S14 & 15 & 0.9936 & 1 \\
2019 & M-S15 & 15 & 0.7708 & 1 \\
2019 & M-S17 & 15 & 0.7097 & 2 \\
2019 & M-S18 & 15 & 0.9998 & 1 \\
2020 & M-S22 & 30 & 1 & 1 \\
2020 & M-S25 & 20 & 0.9974 & 1 \\
2020 & M-S27 & 30 & 1 & 1 \\
2020 & M-S28 & 20 & 0.999 & 1 \\
2020 & M-S31 & 30 & 1 & 1 \\
2020 & M-S33 & 30 & 0.9959 & 1 \\
\hline
\end{tabular}


ethanol. Mothers were then re-released into the area where caught. Genomic DNA was then extracted from tissue dissected from the base of the pleiopods (mothers) or from whole larvae, using a Qiagen DNeasy Blood \& Tissue kit following the standard protocol. Larval exoskeletons were fragmented in a tissue homogenizer (Retsch $\mathrm{GmbH}$ ) before lysis. DNA quantity, purity and integrity were assessed using a Nanodrop ND-1000 spectrophotometer (Thermo Fisher), and through gel electrophoresis.

For maternal assignment and reconstruction of paternal genotypes, a previously published SNP panel of 96 loci was used (Jenkins et al. 2019a). Genotyping was performed at the SNP\&SEQ platform at the Swedish National Genomics infrastructure (Uppsala University) through the iPLEX/ MassArray system. All mothers were genotyped as two technical replicates, in order to assess the reliability of the genotype data. A total of 309 larvae from the 17 mothers were genotyped. Additionally, DNA from 10 non-related adult individuals, sampled 2007 at Kåvra on the Swedish west coast for a previous study (Huserbråten et al. 2013), was extracted and genotyped in order to test for putative false positive assignments. Four out of the 96 loci did not produce a viable assay (H_gam_15531, H_gam_4173, H_ gam_31462, H_gam_35584), leaving 92 loci for genotyping. Seven loci had genotyping rates of $0 \%$ (H_gam_11183, H_ gam_15109, H_gam_54240, H_gam_55142, H_gam_63798, H_gam_65064, H_gam_65376), and out of the well-genotyped loci, 7 were monomorphic (H_gam_25580, H_ gam_58053, H_gam_32362, H_gam_53889, H_gam_32358, H_gam_8953, H_gam_22365), leaving 78 informative SNP markers.

The genotype data were analyzed using the commandline version of COLONY, Version 2.0.6.6, Build 20200830 (Wang and Santure 2009; Jones and Wang 2010). Individual larvae with $0 \%$ genotyping rate $(\mathrm{n}=7)$ were pruned from the dataset, leaving 302 well-genotyped larvae plus the ten additional false assignment controls $(\mathrm{N}=9-30$ per mother, see Table 1). The settings used were: Not updating allele frequency; dioecious species; no inbreeding; diploid species; polygamy for males, monogamy for females (assumed as previous studies have shown multiple paternity to be extremely rare, see discussion); no clone inference; full sibship size scaling; strong prior on sibship size, mean paternal and maternal sibship size 1.0; estimate population allele frequencies from the dataset, while taking relationships into account; 1 run; run length 2; monitor by iteration, interval 100,000; use full likelihood; high precision for full likelihood; probability of dad included 0 ; probability of mum included 0.95 ; paternity exclusion threshold 1 ; maternity exclusion threshold 5; no known dyads, sibships or exclusions. The last setting was used despite knowledge of known sibships, as the purpose was to test the power to detect sibships. Locus-specific genotyping error rates were calculated and incorporated into the parentage analysis using default settings. Finally, COLONY was run three times with the same settings, in order to estimate the robustness of the results.

\section{Results}

Genotyping rates per individual and locus are given in Supplementary Tables S1 and S2. Overall, the mean genotyping rate per individual was $90.2 \%$ (not including the 7 individuals with $0 \%$ genotyping rate). The mean genotyping rate per locus was $95.7 \%$ (not including the 7 loci with $0 \%$ genotyping rate). 27 out of the 78 polymorphic SNPs were significantly deviating from Hardy-Weinberg equilibrium (Supplementary Table S2), which was expected as the dataset does not consist of randomly mating individuals. All 17 technical replicates had identical genotypes as their counterparts at all loci with called genotypes (Supplementary Table S3). The full genotype dataset is given in Supplementary Table S4.

\section{Maternal assignment}

The three runs of COLONY gave identical results, indicating a robust signal in the dataset. All larvae with genotyped mothers $(100 \%, \mathrm{n}=302)$ could be correctly assigned to their mothers (Supplementary Table S5). For 14 out of the 17 mothers, larvae were assigned with $>95 \%$ probability, while for mother S9 the probability was $93.5 \%$ and for mothers S15 and S17 the probabilities were $77.1 \%$ and $71.0 \%$, respectively (Table 1). The ten genotyped control individuals without genotyped mothers were not assigned to any of the genotyped mothers. Rather, they were assigned to six different imputed maternal genotypes (ID \#1-\#6; Supplementary Table S5), indicating the possibility of some halfsibship among these individuals. However, the assignment probabilities of these individuals were generally low (Supplementary Table S5).

\section{Imputation of paternal genotypes}

The power to confidently impute paternal genotypes $\left(\mathrm{P}_{\text {genotype }}>0.95\right)$ depended strongly on the number of genotyped larvae $(\mathrm{p}<0.001)$, with a dramatic decrease below 9 larvae. With 20 larvae or more, essentially all paternal genotypes could be imputed (Fig. 1; Table 2). The paternal genotype imputation inferred 29 fathers for the whole dataset, of which 10 were assigned to the control lobsters with no mother genotypes present (Table 2). For the remaining larvae, most were inferred to be full siblings. Only two mothers presented larvae from more than one father (M-S13 
Fig. 1 The proportion of wellimputed paternal genotypes $(\mathrm{P}$ most probable genotype $>0.95$ ) as a function of the number of genotyped larvae

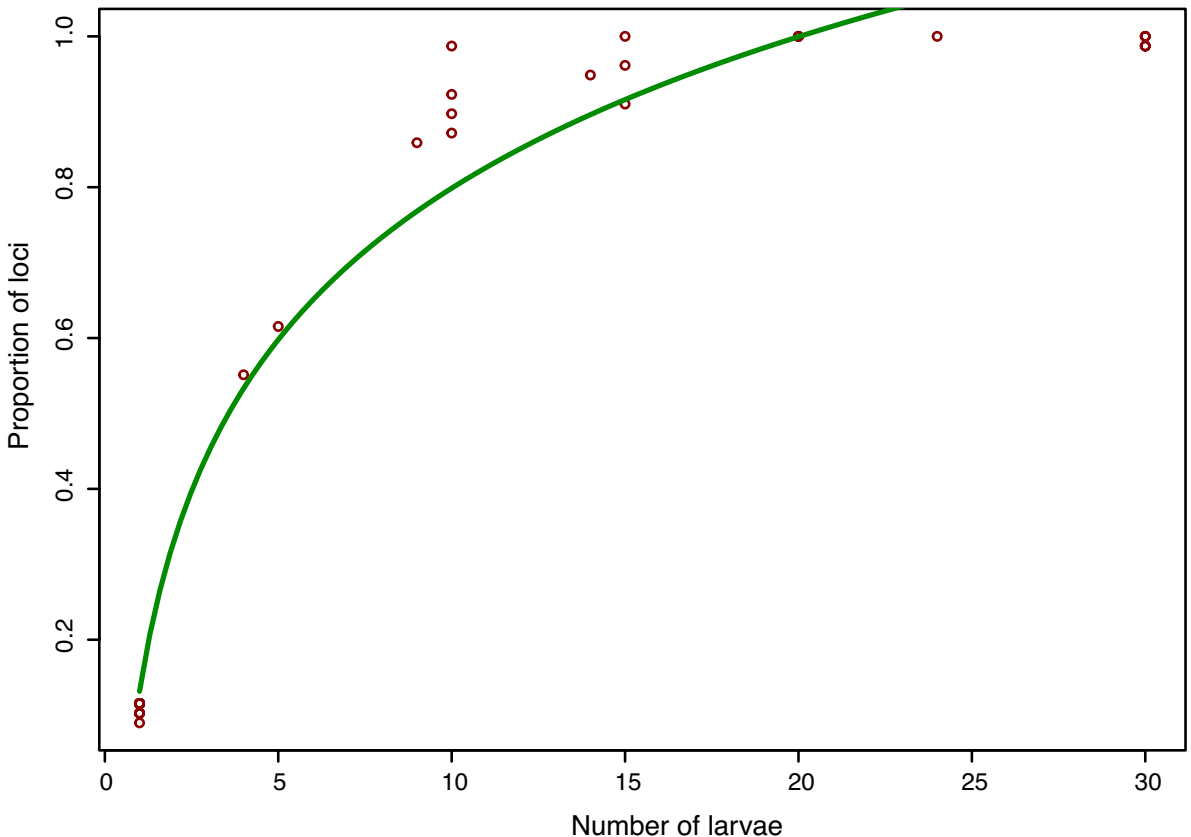

and M-S17; Table 1). All imputed paternal genotypes are given in Supplementary Table S6. In addition, the imputed maternal genotypes for the control lobsters are given in Supplementary Table S7.

\section{Discussion}

Despite the reduced number of SNPs that produced informative data $(n=78$ out of 96$)$, we were here able to correctly assign all of our juvenile individuals to the correct mother, while not incorrectly assign any of the unrelated control individuals to any of the mothers in the dataset. Two of the mothers (S15 and S17) had lower assignment probabilities, despite not deviating in terms of genotyping rate, heterozygosity or genetic distance from others. One of the S15 and two of the $\mathrm{S} 17$ larvae had low genotyping rates, which possibly could have affected the assignment scores. However, this was also true for one larva from mother S14, where the assignment score was high, leaving the reason unclear. Further, the success of maternal assignment was independent of the number of larvae sampled from each mother. SNP panels of similar size have successfully been used to infer parentage in restocking efforts of fish species such as bass (Zhao et al. 2018) and rainbow trout (Liu et al. 2016), and have also been shown to work well to infer parentage in selected shrimp lines in aquaculture (Sellars et al. 2014). However, this is to our knowledge the first time a SNP panel has been used to infer motherhood in absence of known fathers in a restocking effort in any crustacean species to date. The results gained here suggest that using this SNP panel to assess parentage of lobsters caught in a restocking area would work well.

The reconstruction of the paternal genotypes, however, proved to be dependent on the number of genotyped larvae. This is not surprising, as the power to impute the paternal genotype depends on the probability of sampling an alternate allele in the larval pool. A potential confounding factor here could also be that the larvae coming from small sibling groups were also the ones with no mother present in the dataset, meaning that both maternal and paternal genotypes had to be imputed, further complicating the imputation process. Nevertheless, we here found that using ten larvae per family generate a confident imputation of paternal genotypes. We also found that in 15 out of the 17 larval clutches examined $(88 \%)$, there was only one father, whereas in the remaining two clutches, the larvae were indicated to be originating from two fathers. In one of these (S-17), only one larva was inferred to be of a different paternity, and that larva was not very well genotyped (25\% genotyping rate). In the other brood (S-13), however, seven larvae were well genotyped (ca. $90 \%$ genotyping rate), of which four were inferred to come from one father and three from another, with assignment probabilities of 98\%. Ellis et al. (2015a) found no multiple paternity in 34 analyzed broods, while Sørdalen et al. (2018) genotyped 97 females with broods finding only two (2\%) to have two fathers, both concluding that multiple paternal fertilization is highly unusual in $H$. gammarus. Thus, the present data further support that multiple paternity is very rare in this species.

Our results show that this SNP panel is a good choice for determining the success of the ongoing restocking effort on the west coast of Sweden, and possibly also in 
Table 2 Statistics of imputed paternal genotypes (“\#” denotes imputed mothers and “*” denotes imputed fathers)

\begin{tabular}{|c|c|c|c|c|}
\hline Father ID & $\begin{array}{l}\text { Proportion of loci } \\
\text { with } P_{\text {genotype }} \geq 95 \%\end{array}$ & Mother ID & $\begin{array}{l}\text { Propor- } \\
\text { tion of } \\
\text { larvae }\end{array}$ & $\mathrm{N}_{\text {larvae }}$ \\
\hline$* 1$ & 0.115384615 & $\# 1$ & 1 & 1 \\
\hline$* 2$ & 0.115384615 & $\# 2$ & 0.5 & 1 \\
\hline$* 3$ & 0.102564103 & \#3 & 1 & 1 \\
\hline$* 4$ & 0.115384615 & $\# 4$ & 0.33 & 1 \\
\hline$* 5$ & 0.102564103 & \#5 & 1 & 1 \\
\hline$* 6$ & 0.102564103 & \#4 & 0.33 & 1 \\
\hline$* 7$ & 0.115384615 & \#6 & 0.5 & 1 \\
\hline$* 8$ & 0.115384615 & $\# 6$ & 0.5 & 1 \\
\hline$* 9$ & 0.115384615 & \#4 & 0.33 & 1 \\
\hline$* 10$ & 0.115384615 & $\# 2$ & 0.5 & 1 \\
\hline$* 11$ & 1 & M-S1 & 1 & 24 \\
\hline$* 12$ & 0.551282051 & M-S13 & 0.44 & 4 \\
\hline$* 13$ & 0.615384615 & M-S13 & 0.56 & 5 \\
\hline$* 14$ & 0.91025641 & M-S14 & 1 & 15 \\
\hline *15 & 0.961538462 & M-S15 & 1 & 15 \\
\hline$* 16$ & 0.948717949 & M-S17 & 0.93 & 14 \\
\hline$* 17$ & 0.08974359 & M-S17 & 0.07 & 1 \\
\hline *18 & 1 & M-S18 & 1 & 15 \\
\hline *19 & 0.923076923 & $\mathrm{M}-\mathrm{S} 2$ & 1 & 10 \\
\hline *20 & 1 & M-S22 & 1 & 30 \\
\hline$* 21$ & 1 & M-S25 & 1 & 20 \\
\hline$* 22$ & 0.987179487 & M-S27 & 1 & 30 \\
\hline$* 23$ & 1 & M-S28 & 1 & 20 \\
\hline$* 24$ & 1 & M-S31 & 1 & 30 \\
\hline$* 25$ & 0.987179487 & M-S33 & 1 & 30 \\
\hline$* 26$ & 0.871794872 & M-S5 & 1 & 10 \\
\hline$* 27$ & 0.897435897 & M-S6 & 1 & 10 \\
\hline$* 28$ & 0.858974359 & M-S8 & 1 & 9 \\
\hline$* 29$ & 0.987179487 & M-S9 & 1 & 10 \\
\hline
\end{tabular}

other areas in Europe. As all mothers used in the ongoing restocking effort have been sampled for DNA, it is likely that wild-caught lobsters from the fall of 2022 and onward will be able to be assigned to these mothers if they are indeed released ones, and that they will not assign to these mothers if they are wild-raised ones. Additionally, as the mothers were released back into the area, the genetic panel will be an important tool to investigate whether these individuals are re-caught in future efforts. We also conclude that as the restocking effort continues, pleiopods from all mothers used should be sampled and stored in ethanol, for future reference. Further, if there is a desire to also impute paternal genotypes from the ongoing efforts, for example to learn if the fathers of the lab-raised lobsters are being caught, then a minimum of ten larvae from each released clutch should also be preserved in ethanol.
Supplementary Information The online version contains supplementary material available at https://doi.org/10.1007/s12686-021-01234-3.

Acknowledgements The lobster material was provided through the project "Kläckning och uppfödning av utsättningsbara hummeryngel" by Symbioscentrum, Sotenäs municipality and financed by the Swedish board of agriculture and European Maritime and fisheries fund, and by the European Regional Development Fund (Kattegatt-Skagerrak region), through the project "MarGen II-Kapacitetsopbygning for $\emptyset$ get bæredygtig vækst ved akvatiske miljøer i Kattegat-Skagerrak". Per-Olof Samuelsson is thanked for technical assistance. Genotyping was performed by the SNP\&SEQ Technology Platform in Uppsala (http://www.genotyping.se). The facility is part of the National Genomics Infrastructure supported by the Swedish Research Council for Infrastructures and Science for Life Laboratory, Sweden. The SNP\&SEQ Technology Platform is also supported by the Knut and Alice Wallenberg Foundation.

Author contributions PDW and CA designed the study and performed genetic analyses. LS, IC, SPE and KS were responsible for the rearing of lobster juveniles. PDW wrote the manuscript. All co-authors contributed to the final version of the manuscript.

Funding Open access funding provided by University of Gothenburg. Funding for this research was provided by the project "Kläckning och uppfödning av utsättningsbara Hummeryngel" financed by the Swedish board of agriculture and European Maritime and Fisheries Fund, the European Regional Development Fund Project "MarGen II-Kapacitetsopbygning for $\varnothing$ get bæredygtig vækst ved akvatiske miljøer i Kattegat-Skagerrak", and from the municipality of Sotenäs.

Data availability All data generated in this project is provided in the supplementary materials.

Code availability Not applicable.

\section{Declarations}

Conflict of interest The authors declare that they have no conflict of interest.

Ethical approval Not applicable for lobsters.

Consent to participate Not applicable.

Consent for publication All co-authors have given their consent for publication.

Open Access This article is licensed under a Creative Commons Attribution 4.0 International License, which permits use, sharing, adaptation, distribution and reproduction in any medium or format, as long as you give appropriate credit to the original author(s) and the source, provide a link to the Creative Commons licence, and indicate if changes were made. The images or other third party material in this article are included in the article's Creative Commons licence, unless indicated otherwise in a credit line to the material. If material is not included in the article's Creative Commons licence and your intended use is not permitted by statutory regulation or exceeds the permitted use, you will need to obtain permission directly from the copyright holder. To view a copy of this licence, visit http://creativecommons.org/licenses/by/4.0/. 


\section{References}

Bryhn A, Sundelöf A, Lingman A et al (2020) Fisk-och skaldjursbestånd i hav och sötvatten 2019-Resursöversikt. Swedish Agency for Marine and Water Management, Gothenburg, Sweden. ISBN 978-91-88727-63-3

Camp EV, Lorenzen K, Ahrens RNM, Barbieri L, Leber KM (2013) Potentials and limitations of stock enhancement in marine recreational fisheries systems: an integrative review of Florida's Red Drum enhancement. Rev Fish Sci 21:388-402

Ellis CD, Hodgson DJ, André C et al (2015a) Genotype reconstruction of paternity in European lobsters (Homarus gammarus). PLoS One 10:1-14

Ellis CD, Hodgson DJ, Daniels CL et al (2015b) European lobster stocking requires comprehensive impact assessment to determine fishery benefits. ICES J Mar Sci 72:i35-i48

FAO (2020) The state of world fisheries and aquaculture 2020. Sustainability in action. Food and Agriculture Organization of the United Nations, Rome, Italy. ISBN 978-92-5-132692-3

Flanagan SP, Jones AG (2019) The future of parentage analysis: from microsatellites to SNPs and beyond. Mol Ecol 28:544-567

Halverson MA (2008) Stocking trends: a quantitative review of governmental fish stocking in the United States, 1931 to 2004. Fisheries 33:69-75

Huserbråten MBO, Moland E, Knutsen H et al (2013) Conservation, spillover and gene flow within a network of Northern European marine protected areas. PLoS One 8:1-10

Jenkins TL, Ellis CD, Stevens JR (2019a) SNP discovery in European lobster (Homarus gammarus) using RAD sequencing. Conserv Genet Resour 11:253-257

Jenkins TL, Ellis CD, Triantafyllidis A, Stevens JR (2019b) Single nucleotide polymorphisms reveal a genetic cline across the northeast Atlantic and enable powerful population assignment in the European lobster. Evol Appl 12:1881-1899

Jones OR, Wang J (2010) COLONY: a program for parentage and sibship inference from multilocus genotype data. Mol Ecol Resour 10:551-555
Kitada S (2018) Economic, ecological and genetic impacts of marine stock enhancement and sea ranching: a systematic review. Fish Fish 19:511-532

Liu S, Palti Y, Gao G, Rexroad CE (2016) Development and validation of a SNP panel for parentage assignment in rainbow trout. Aquaculture 452:178-182

Nzau Matondo B, Séleck E, Dierckx A et al (2019) What happens to glass eels after restocking in upland rivers? A long-term study on their dispersal and behavioural traits. Aquat Conserv Mar Freshw Ecosyst 29:374-388

Perkins HC (1972) Developmental rates at various temperatures of embryos of the northern lobster (Homarus americanus MilneEdwards). Fish Bull 70:95-99

Sellars MJ, Dierens L, Mcwilliam S et al (2014) Comparison of microsatellite and SNP DNA markers for pedigree assignment in Black Tiger shrimp, Penaeus monodon. Aquac Res 45:417-426

Sørdalen TK, Halvorsen KT, Harrison HB et al (2018) Harvesting changes mating behaviour in European lobster. Evol Appl 11:963-977

Sundelöf A, Bartolino V, Ulmestrand M, Cardinale M (2013) Multiannual fluctuations in reconstructed historical time-series of a European lobster (Homarus gammarus) population disappear at increased exploitation levels. PLoS One 8:e58160

Taylor MD, Chick RC, Lorenzen K et al (2017) Fisheries enhancement and restoration in a changing world. Fish Res 186:407-412

Wang J, Santure AW (2009) Parentage and sibship inference from multilocus genotype data under polygamy. Genetics 181:1579-1594

Zhao H, Li C, Hargrove JS et al (2018) SNP marker panels for parentage assignment and traceability in the Florida bass (Micropterus floridanus). Aquaculture 485:30-38

Publisher's Note Springer Nature remains neutral with regard to jurisdictional claims in published maps and institutional affiliations. 